\title{
Structural Polymorphism of Resorcinarene Assemblies
}

Shota Fujï ${ }^{* *}$, Rika Miyake ${ }^{\dagger}$, Liliana de Campo

†Department of Chemistry and Biochemistry, University of Kitakyushu, 1-1 Hibikino,

Kitakyushu, Fukuoka 808-0135, Japan

‡Australian Centre for Neutron Scattering (ACNS), Australian Nuclear Science and Technology

Organisation (ANSTO), Lucas Heights, NSW 2234, Australia

*Corresponding author

Table of Contents

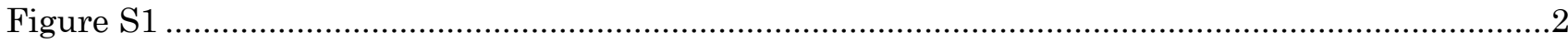

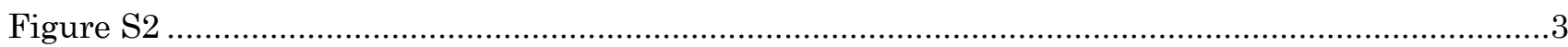

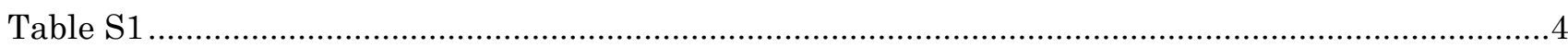

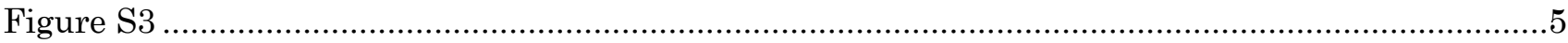

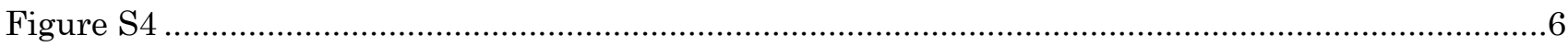

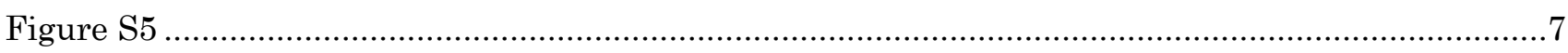

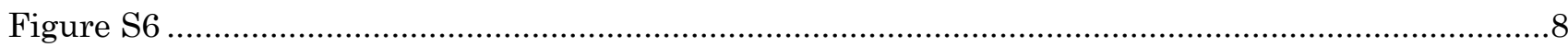

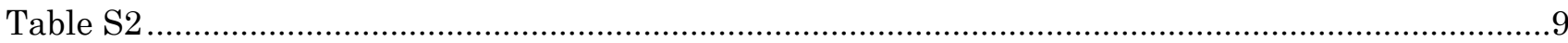


Figure S1

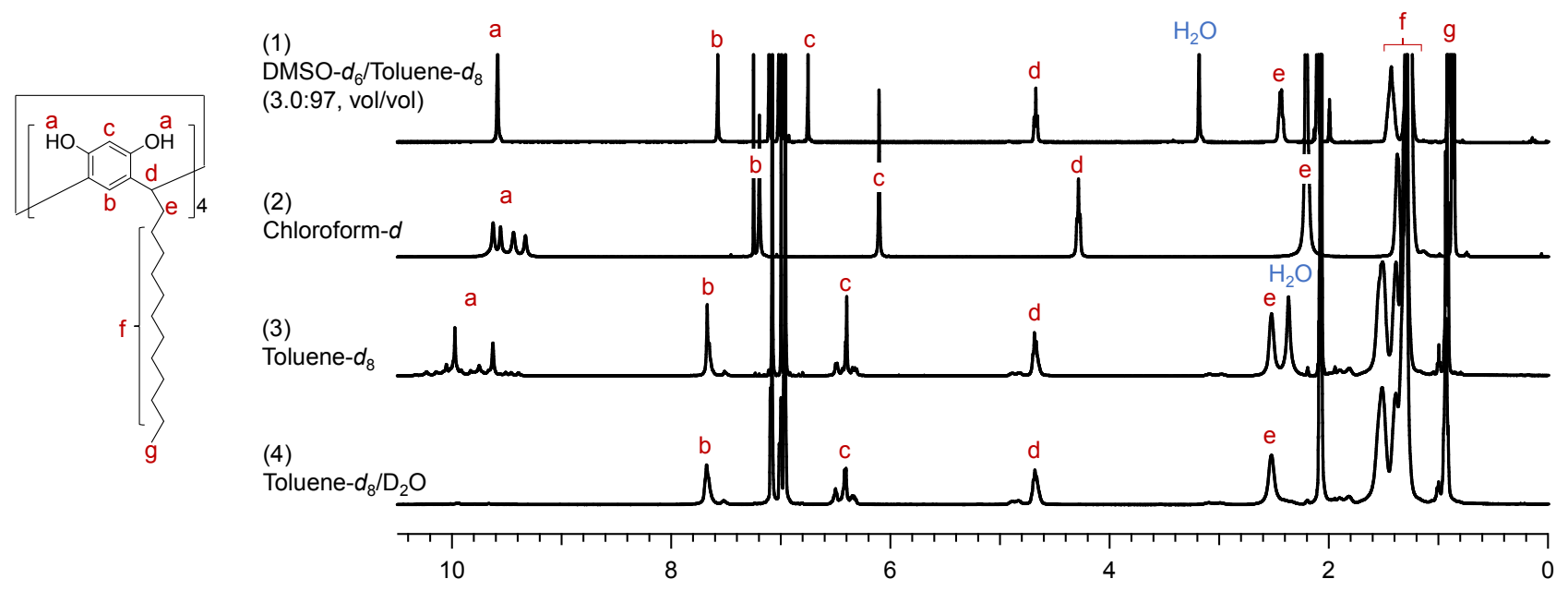

Figure S1. ${ }^{1} \mathrm{H}-\mathrm{NMR}$ spectra of C11Re in (1) toluene-d8/DMSO-d6 (97/3.0 vol\%), (2) chloroform-d, (3) toluene-d8, and (4) toluene-d8 treated with D2O. 
Figure S2
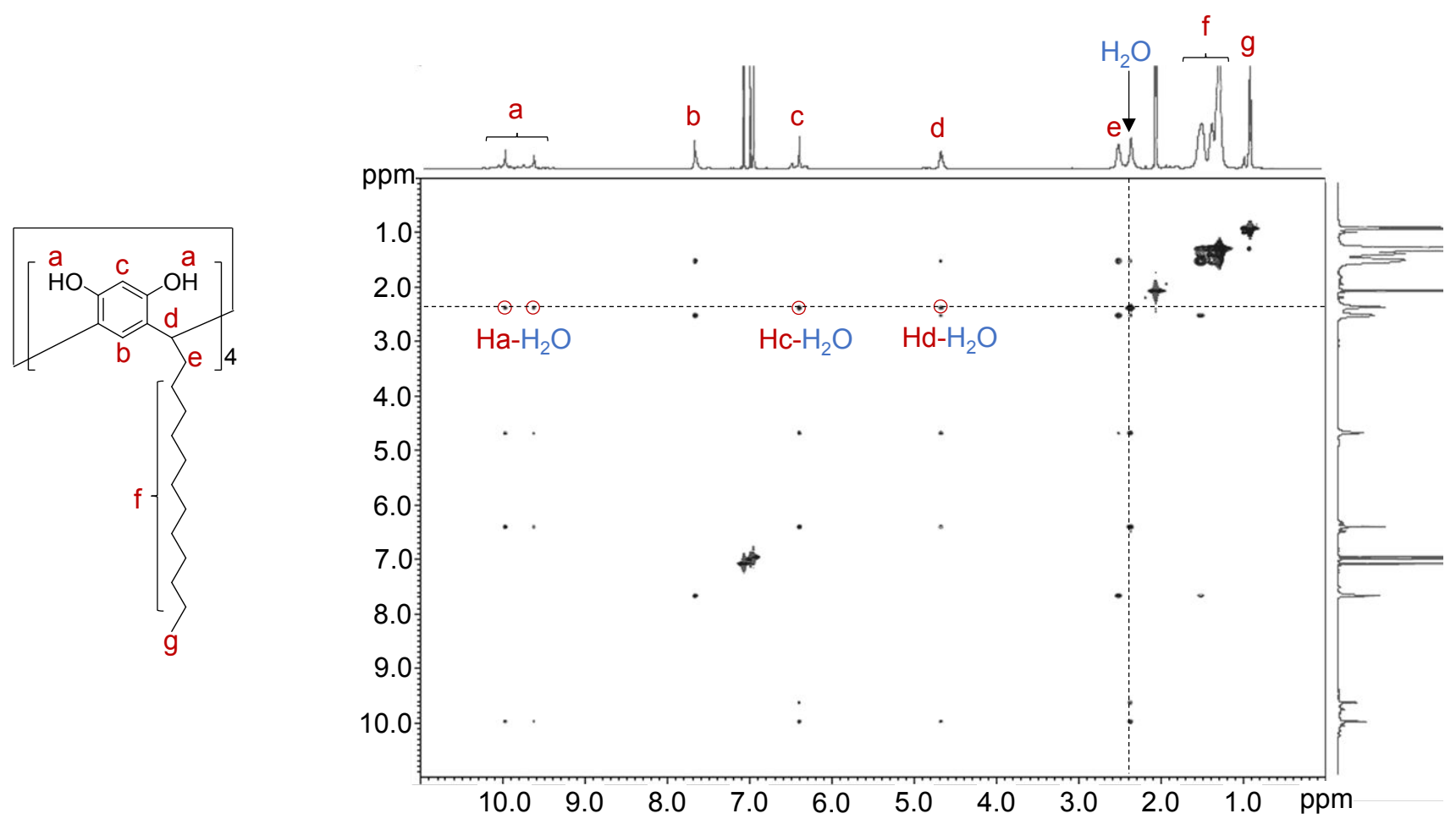

Figure S2. ${ }^{1} \mathrm{H}-{ }^{1} \mathrm{H}$ NOESY NMR of C11Re in toluene- $d_{8}$. 
Table S1

Table S1. SANS Fitting Parameters, $R_{\mathrm{g}}$, and $M_{\mathrm{w}}$ for C11Re Assemblies in Chloroform- $d$ and Toluene$d_{8}$ at $25^{\circ} \mathrm{C}$

\begin{tabular}{cccccccc}
\hline Solvent & $\begin{array}{c}R_{\mathrm{c}} \\
{[\mathrm{nm}]}\end{array}$ & $\begin{array}{c}R_{\mathrm{s}} \\
{[\mathrm{nm}]}\end{array}$ & $\begin{array}{c}\rho_{\mathrm{c}} \\
{\left[\mathrm{cm}^{-2}\right]}\end{array}$ & $\begin{array}{c}\rho_{\mathrm{s}} \\
{\left[\mathrm{cm}^{-2}\right]}\end{array}$ & $\begin{array}{c}R_{\mathrm{g}} \\
{[\mathrm{nm}]}\end{array}$ & $\begin{array}{c}M_{\mathrm{w}} \\
{\left[10^{3} \mathrm{~g} / \mathrm{mol}\right]}\end{array}$ & $N_{\mathrm{agg}}$ \\
\hline Chloroform- $d$ & 0.900 & 1.95 & $3.16 \times 10^{10}$ & $6.01 \times 10^{9}$ & $1.57 \pm 0.02$ & $6.53 \pm 0.10$ & $5.8(\sim 6.0)$ \\
Toluene- $d_{8}$ & - & 2.00 & - & $6.01 \times 10^{9}$ & $1.62 \pm 0.07$ & $9.33 \pm 0.30$ & $8.3(\sim 8.0)$ \\
\hline
\end{tabular}

The values of the coherent neutron scattering length of the deuterated solvents were taken from the NIST database ${ }^{2}$, which was employed as the $\rho_{\mathrm{c}}$ in the fitting for SANS profiles. 
Figure S3

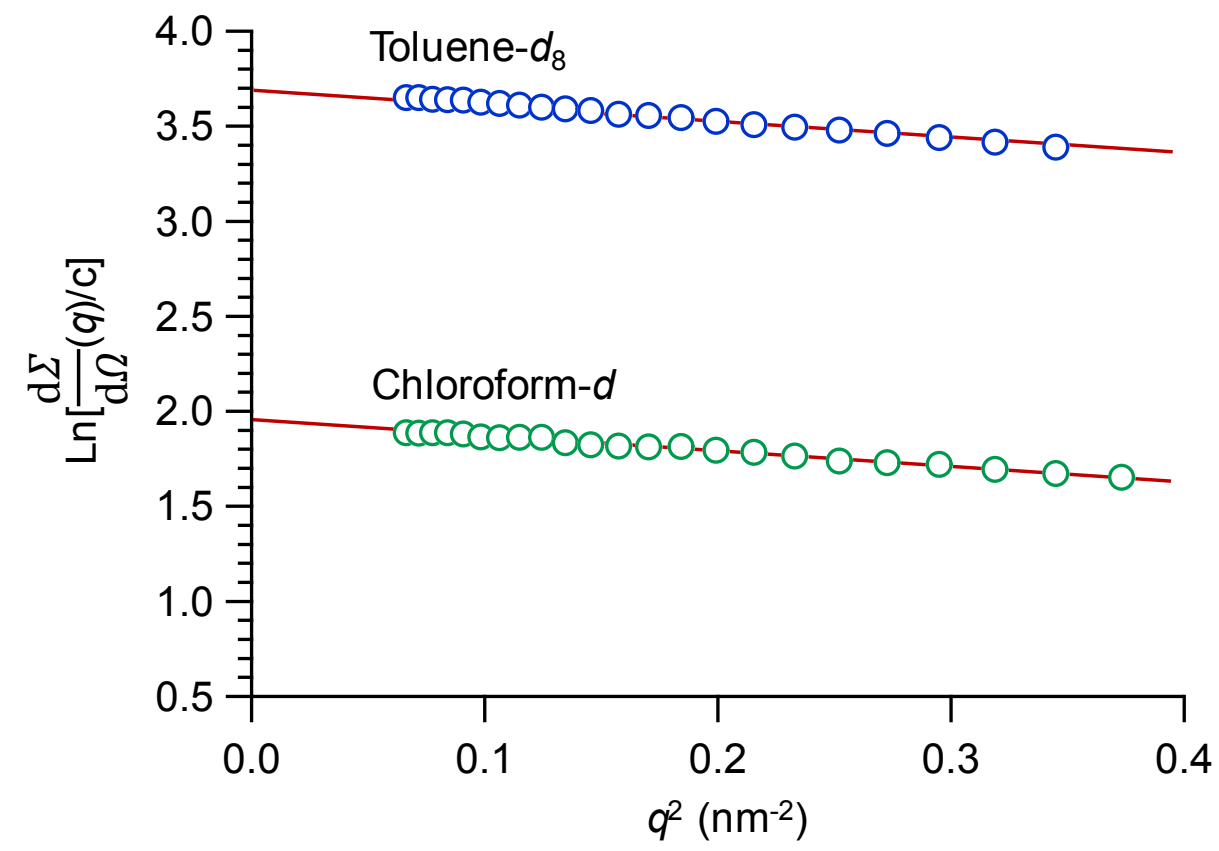

Figure S3. The Guinier plot [i.e., $\ln \frac{\mathrm{d} \delta}{\mathrm{d} \Omega}(q) c^{-1}$ vs. $q^{2}$ ] derived from the SANS profile of C11Re assemblies in toluene- $d_{8}$ (blue) and chloroform- $d$ (green). 
Figure S4

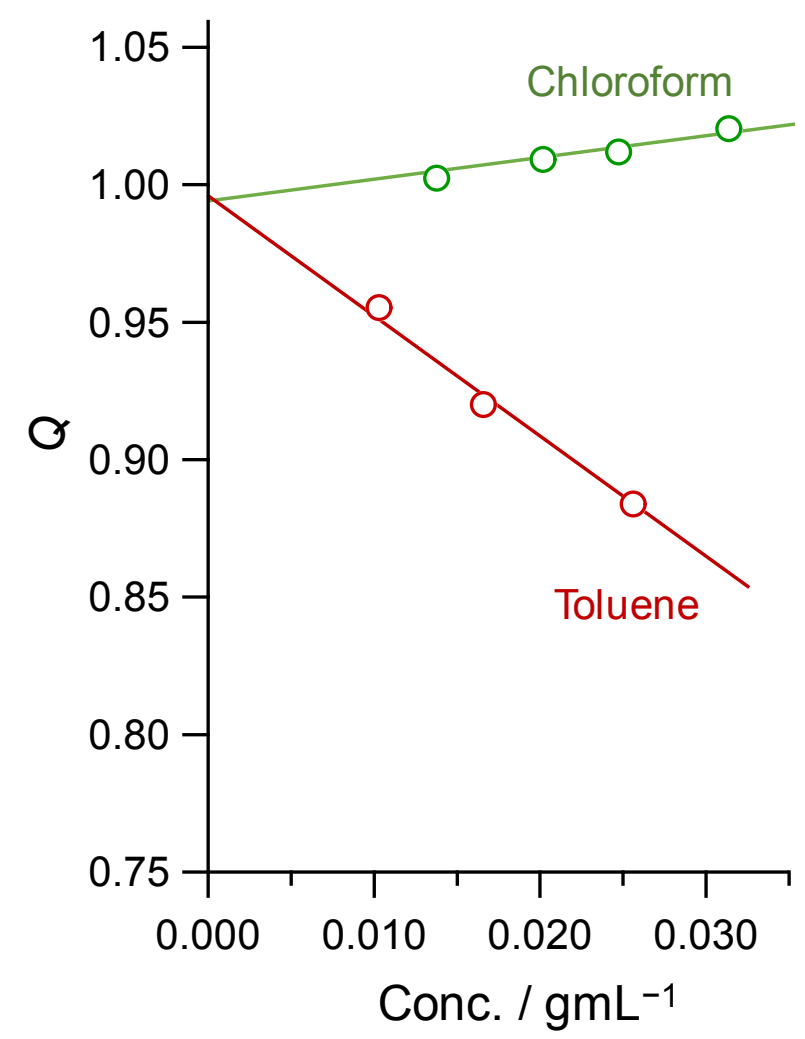

Figure S4. The concentration dependence of $Q\left(=M_{\mathrm{w}, \mathrm{App}} / M_{\mathrm{z}, \mathrm{App}}\right)$ determined by $\mathrm{AUC}$ measurements for C11Re assemblies in toluene (red) and chloroform (green) at $25^{\circ} \mathrm{C}$. 
Figure S5

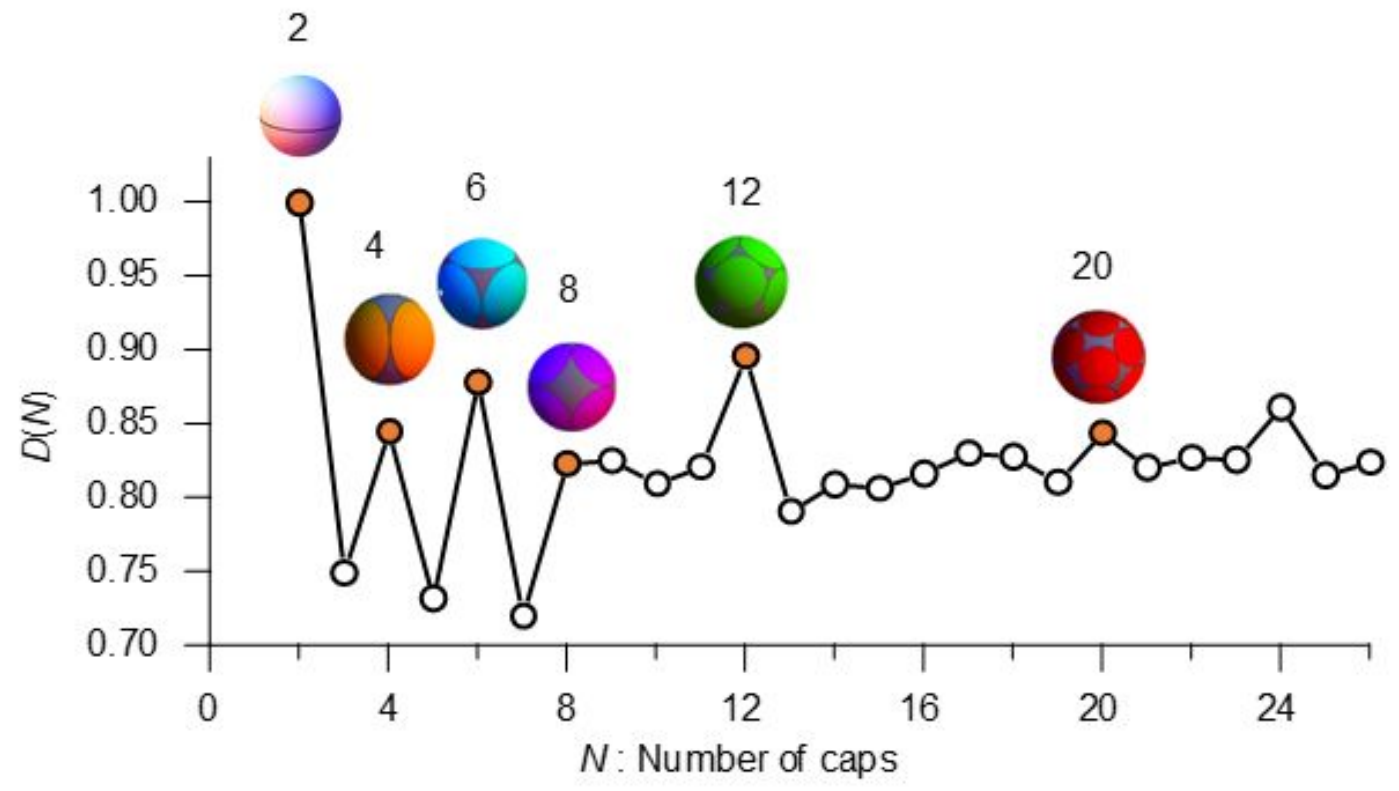

Figure S5. $D(N)$ for $N$ ranging from 2 to 26. Certain numbers produce a local maximum and are identical to the number of the vertices of Platonic solids. 
Figure S6
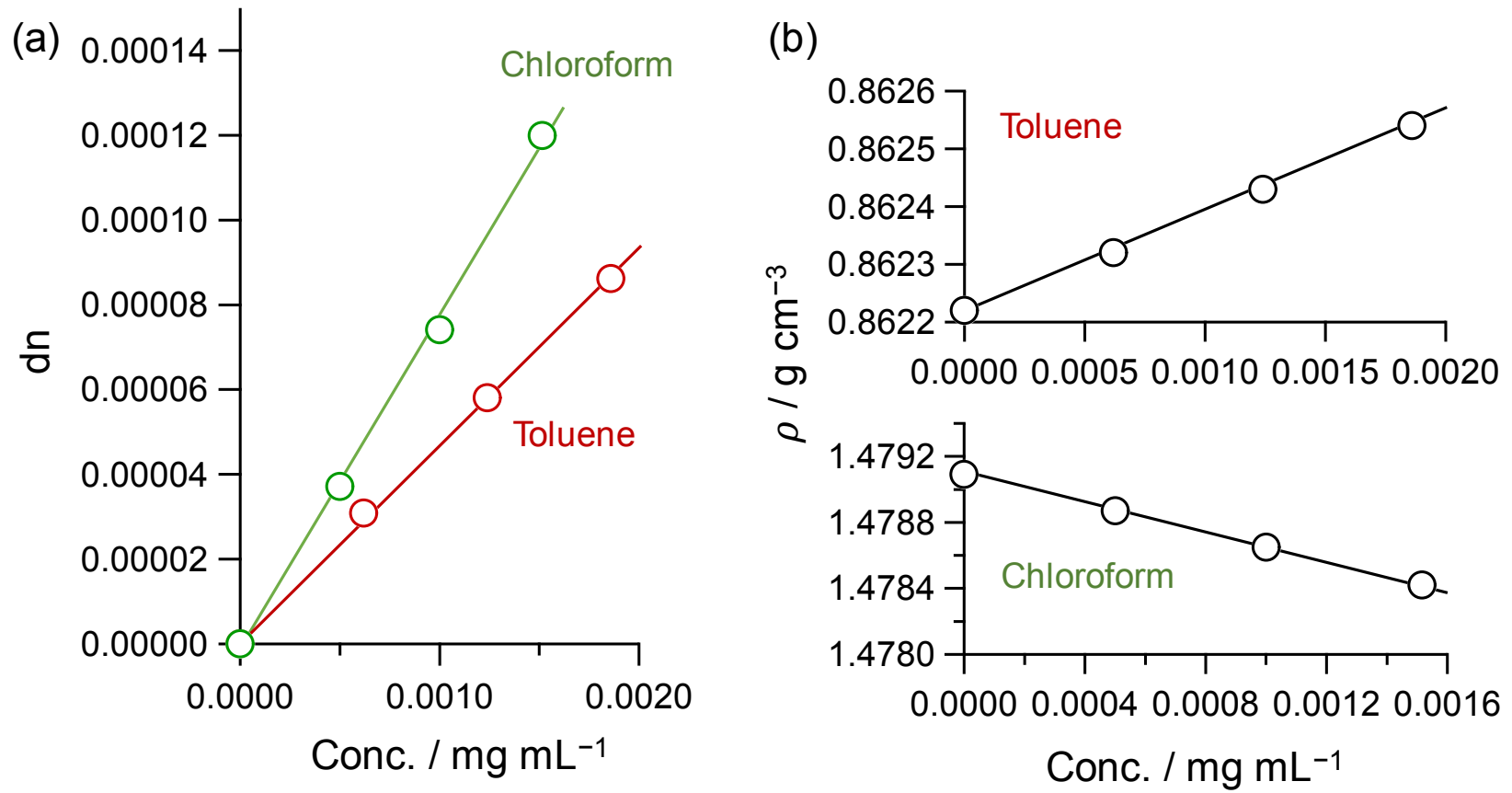

Figure S6. Concentration dependence of refractive index increment (a) and density increment (b) for $\mathrm{C} 11 \mathrm{Re}$ assembly in toluene (red) and chloroform (green) at $25^{\circ} \mathrm{C}$. The determined value of $\mathrm{dn} / \mathrm{dc}$ and $\bar{v}$ for the capsule are summerized in Table $\mathrm{S} 2$. 
Table S2

Table S2. Refractive Index Increment and Partial Specific Volume of C11Re Assemblies in Apolar Solvents.

\begin{tabular}{ccc}
\hline Solvent & $\mathrm{dn} / \mathrm{dc}\left[\mathrm{cm}^{-3} \mathrm{~g}\right]$ & $\bar{v}\left[\mathrm{~cm}^{-3} \mathrm{~g}\right]$ \\
\hline Toluene & 0.0758 & 0.960 \\
Chloroform & 0.0467 & 0.975 \\
\hline
\end{tabular}

